\title{
Revisiting the loading dose of amikacin for patients with severe sepsis and septic shock
}

\author{
Fabio Silvio Taccone1, Pierre-François Laterre², Herbert Spapen³ ${ }^{3}$, Thierry Dugernier ${ }^{4}$, Isabelle Delattre5 ${ }^{5}$ Brice Layeux ${ }^{6}$, \\ Daniel De Backer ${ }^{1}$, Xavier Wittebole2, Pierre Wallemacq ${ }^{5}$, Jean-Louis Vincent ${ }^{1}$ and Frédérique Jacobs*6
}

\begin{abstract}
Introduction: It has been proposed that doses of amikacin of $>15 \mathrm{mg} / \mathrm{kg}$ should be used in conditions associated with an increased volume of distribution $\left(V_{d}\right)$, such as severe sepsis and septic shock. The primary aim of this study was to determine whether $25 \mathrm{mg} / \mathrm{kg}$ (total body weight) of amikacin is an adequate loading dose for these patients.

Methods: This was an open, prospective, multicenter study in four Belgian intensive care units (ICUs). All consecutive patients with a diagnosis of severe sepsis or septic shock, in whom amikacin treatment was indicated, were included in the study.

Results: In 74 patients, serum samples were collected before ( $t=0$ h) and 1 hour (peak), 1 hour 30 minutes, 4 hours 30 minutes, 8 hours, and 24 hours after the first dose of amikacin. Blood amikacin levels were measured by using a validated fluorescence polarization immunoassay method, and an open two-compartment model with first-order elimination was fitted to concentrations-versus-time data for amikacin (WinNonlin). In 52 (70\%) patients, peak serum concentrations were $>64 \mu \mathrm{g} / \mathrm{ml}$, which corresponds to 8 times the clinical minimal inhibitory concentration (MIC) breakpoints defined by EUCAST for Enterobacteriaceae and Pseudomonas aeruginosa $(\mathrm{S}<8, \mathrm{R}>16 \mu \mathrm{g} / \mathrm{ml})$. $V_{\mathrm{d}}$ was 0.41 (0.29 to 0.51) L/kg; elimination half-life, 4.6 (3.2 to 7.8 ) hours; and total clearance, 1.98 (1.28 to 3.54) ml/min/kg. No correlation was found between the amikacin peak and any clinical or hemodynamic variable.

Conclusions: As patients with severe sepsis and septic shock have an increased $V_{d}$, a first dose of $\geq 25 \mathrm{mg} / \mathrm{kg}$ (total body weight) of amikacin is required to reach therapeutic peak concentrations. However, even with this higher amikacin dose, the peak concentration remained below therapeutic target levels in about one third of these patients. Optimizing aminoglycoside therapy should be achieved by tight serum-concentration monitoring because of the wide interindividual variability of pharmacokinetic abnormalities.
\end{abstract}

\section{Introduction}

Severe sepsis and septic shock are major causes of morbidity and mortality in intensive care units (ICUs) [1]. Early and appropriate infection control is a priority in the management of sepsis and requires adequate early administration of effective antibiotics with a dosing strategy able to achieve therapeutic concentrations at the site of infection [2,3].

Aminoglycosides are often given as part of empiric therapy for severe sepsis and septic shock, especially if Pseudomonas aeruginosa infection is suspected. Their

*Correspondence: fjacobs@ulb.ac.be

${ }^{6}$ Department of Infectious Diseases, Erasme Hospital, Université Libre de Bruxelles, Route de Lennik 808, 1070 Bruxelles, Belgium

Full list of author information is available at the end of the article use is further supported by the emergence of multidrugresistant bacteria and the lack of new drugs active against these microorganisms [4]. Amikacin is a highly potent, broad-spectrum aminoglycoside that is usually given in association with $\beta$-lactams for the treatment of severe gram-negative infections [5]. Meta-analyses have shown limited and conflicting benefits from this combination therapy [6,7]. However, the paucity of trials including patients with severe sepsis and septic shock precludes any recommendations in this setting, and the different amikacin doses and regimens used may have led to inadequate drug concentrations.

In clinical practice, the ratio between the peak and the minimum inhibitory concentration (MIC) of the causative gram-negative pathogen (peak/MIC) is considered 
to be the parameter that best characterizes the in vivo exposure of the pathogen to serum aminoglycoside concentrations [8,9]. Optimal antibacterial activity is achieved when the peak is 8 to 10 times greater than the MIC [10-12]. Despite a large variance in MIC values for different bacteria, therapy should usually target problematic pathogens in ICU patients, such as Enterobacteriaceae and Pseudomonas aeruginosa. The clinical MIC breakpoint for these pathogens is $8 \mu \mathrm{g} / \mathrm{ml}$ [13], indicating that to optimize the antibacterial activity of amikacin, peak drug concentrations should reach $\geq 64 \mu \mathrm{g} / \mathrm{ml}$. This strategy would allow these "difficult-to-treat" pathogens to be exposed to bactericidal drug concentrations, even when treatment is initiated empirically without any knowledge of specific MICs.

Although aminoglycoside pharmacokinetics (PKs) have been already described for the treatment of ICU infections, studies on optimal regimens in sepsis patients had several limiting factors [14-18]. Few prospective data are available regarding which aminoglycoside dose should be used to optimize aminoglycoside concentrations in ICU patients with severe sepsis and septic shock with multiple organ dysfunction. Also, no data are available about the impact of using ideal body weight (IBW) or total body weight (TBW) on the achievement of optimal peak amikacin concentrations in ICU patients.

The primary aim of this study was to validate a higher dosing regimen for amikacin in patients with severe sepsis and septic shock. We also evaluated the impact of body weight, and specifically of an IBW-compared with a TBW-based regimen, on the optimization of peak amikacin concentrations. Finally, we evaluated whether particular clinical or hemodynamic parameters influenced amikacin PK and propose new recommendations for the loading dose of amikacin in this critically ill population.

\section{Materials and methods Study design, patients, and antibiotic treatment}

This was an open, prospective, multicenter, noncomparative study performed in four polyvalent ICUs from four Belgian hospitals between January 2005 and June 2006. The study protocol was approved by the Ethics Committees of the different hospitals. Written informed consent was obtained from each patient or his or her legal guardian. Patients with a diagnosis of severe sepsis or septic shock according to standard criteria [19], in whom amikacin treatment was indicated, were consecutively enrolled in the study. The aminoglycoside was given in combination with a broad-spectrum $\beta$-lactam (ceftazidime, cefepime, piperacillin-tazobactam, or meropenem), according to local clinical practice. Exclusion criteria were younger than 18 years of age, pregnancy, burns or cystic fibrosis (because of increased $V_{d}$ ), neuromuscular disease, body mass index (BMI) $>40 \mathrm{~kg} / \mathrm{m}^{2}$, chronic renal failure requiring dialysis, amikacin treatment in the previous 2 weeks, and known allergy to aminoglycosides. No patient was included more than once. The study period was limited to the first 24 hours of treatment.

All patients included in the study received a loading dose of $25 \mathrm{mg} / \mathrm{kg}$ of amikacin based on TBW; this regimen was defined for an expected mean $\mathrm{V}_{\mathrm{d}}$ of $0.4 \mathrm{~L} / \mathrm{kg}$ and a target peak of $64 \mu \mathrm{g} / \mathrm{ml}[17,20,21]$. Doses were rounded off at multiples of $125 \mathrm{mg}$. The drug was administered over a 30-min period by using an infusion pump, and the tubing was flushed with $0.9 \%$ sodium chloride after the dose was administered. Blood samples for drug assays were taken immediately before administration $(0 \mathrm{~h})$ and 1

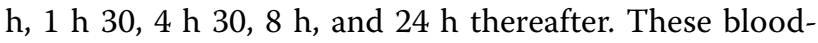
sampling time points are supposed to belong to the elimination phase of the drug. The exact time of sampling was recorded. Blood was collected in a 5-ml plain tube (without anticoagulant). When a clot had completely formed (15 to $30 \mathrm{~min}$ ), the sample was centrifuged at $4^{\circ} \mathrm{C}$, and the serum was stored at $-80^{\circ} \mathrm{C}$ until analysis.

\section{Analytic method for amikacin}

Amikacin concentrations were quantified at the end of the study in a central reference laboratory (St-Luc Hospital) by using a validated fluorescence polarization immunoassay with the TDx analyzer (Abbott Laboratories, Abbott Park, IL, USA). Routine daily quality controls (5, 15 , and $30 \mu \mathrm{g} / \mathrm{ml})$ and calibrators $(3,10,20,35$, and $50 \mu \mathrm{g} /$ $\mathrm{ml}$ ) were provided by Abbott Laboratories. No sample preparation was required for the assay. According to the manufacturer, the limit of quantification (LOQ) is $0.8 \mu \mathrm{g} /$ $\mathrm{ml}$.

\section{PK analysis}

Serum amikacin concentrations were analyzed by using WinNonlin Pharsight Professional Software Version 5.0.1 (Pharsight Corporation, Mountain View, CA, USA). Onecompartment and two-compartment open models with first-order elimination were compared to fit amikacin PKs data. A two-compartment model was selected as the best to fit the Concentration-versus-Time data for amikacin (data not shown). The following pharmacokinetic variables were calculated for each patient: the volume of distribution in the central $\left(\mathrm{V}_{\mathrm{d} 1}\right)$ and in the peripheral $\left(\mathrm{V}_{\mathrm{d} 2}\right)$ compartments, total volume of distribution $\left(\mathrm{V}_{\mathrm{ss}}\right)$, total clearance $(\mathrm{CL})$, elimination half-life $\left(\mathrm{t}_{1 / 2}\right)$, area under the curve (AUC) during the 24 hours, $\mathrm{C}_{\max }$ (maximal concentration calculated by extrapolation of the distribution phase,) and $\mathrm{C}_{\min }$ (concentration $24 \mathrm{~h}$ after the start of infusion). 


\section{PK end points}

Amikacin levels measured 1 hour (= peak) after the onset of perfusion $[8-11,15,21]$ were considered the target concentrations. Optimal peak was considered as $>64 \mu \mathrm{g} / \mathrm{ml}$. The potential toxicity threshold of the drug was determined by a $C_{\min }>5 \mu \mathrm{g} / \mathrm{ml}[15,16]$. However, no evaluation of changes in renal function was performed after the first day of therapy.

\section{Weight estimation}

Body weight was considered on the day of amikacin administration. TBW was taken from medical files for patients admitted from the floor or the operating room; in case of admission through the Emergency Department, institutional databases with recent hospitalizations were used. TBW was also asked directly of the patients, whenever possible. TBW was estimated by doctors and nurses in 10 patients. IBW was calculated according to Devine's formula [22]. Corrected body weight (DW) for patients with BMI $<20$ and $>28 \mathrm{~kg} / \mathrm{m}^{2}$ was calculated according to previous recommendations [23-25]: for BMI $>28 \mathrm{~kg} / \mathrm{m}^{2}$, $\mathrm{DW}=0.4 \times(\mathrm{TBW}-\mathrm{IBW})+\mathrm{IBW}$; for BMI $<20 \mathrm{~kg} / \mathrm{m}^{2}$, $\mathrm{DW}=1.13 \times \mathrm{IBW}$. By using the same PK model obtained with a TBW-based regimen, simulations of individual PK profiles were performed to assess the effect of IBW- and DW-based regimens on peak and $\mathrm{C}_{\min }$ concentrations.

\section{Data collection}

Demographic data, comorbidities, and admission diagnoses were collected in all patients. Disease severity was characterized by the Acute Physiology and Chronic Health Evaluation (APACHE) II score [26]. Organ dysfunction was assessed by using the Sequential Organ Failure Assessment (SOFA) score [27] on the first day of antibiotic treatment. Positive microbiologic cultures were recorded. Site of infection was defined according to the Centers for Disease Control definitions [28]. Biologic data, including coagulation parameters, complete blood count, electrolyte, urea, creatinine, bilirubin, total protein and albumin concentrations, myocardial and liver enzymes, and C-reactive protein (CRP) concentrations, were recorded at inclusion and at 24 hours. Creatinine clearance $(\mathrm{CrCl})$ was estimated with the Cockcroft and Gault equation by using TBW [29]. Renal dysfunction was considered when $\mathrm{CrCl}$ was $<50 \mathrm{ml} / \mathrm{min}$ [30]. Acute renal failure was defined as a renal SOFA score $>2$ (creatinine $>3.0 \mathrm{mg} / \mathrm{dl}$ and/or urine output $<500 \mathrm{ml} /$ day) and/ or need for renal replacement therapy [27]. Other recorded parameters were the use of adrenergic drugs, mechanical ventilation, renal support, 24-hour fluid balance, length of ICU stay, ICU mortality, and cause of death. Hemodynamic and blood-gas analysis data were collected at baseline and 8 and 24 hours after the start of the protocol.

\section{Statistical analysis}

Statistical analyses were performed by using the SPSS 13.0 for the Windows NT software package (SPSS Inc. 2004). Descriptive statistics were computed for all study variables. A Kolmogorov-Smirnov test was used, and histograms and normal-quantile plots were examined to verify the normality of distribution of continuous variables. Discrete variables were expressed as counts (percentage), and continuous variables, as mean \pm SD or median [25th75th percentiles]. Demographics and clinical differences between study groups were assessed by using a $X^{2}$, Fisher's Exact test, Student's $t$ test, or Mann-Whitney $U$ test, as appropriate. The Pearson's $(r)$ correlation coefficient was used to determine linear correlation. Association between variables was tested by simple regression analysis and coefficient of determination $\left(R^{2}\right)$ in the case of nonlinear correlation. An univariate analysis followed by a multivariate stepwise linear-regression analysis, including all the collected variables, was also performed to predict the amikacin peak. A value of $P<0.05$ was considered to be statistically significant.

\section{Results}

\section{Characteristics of patients}

We enrolled 74 patients (Table 1). The median APACHE II score was 21, and the median SOFA score on admission was 8 . Fifty-six (76\%) patients were treated with mechanical ventilation, and 20 (27\%) patients had acute renal failure. Overall ICU mortality was $36 \%$; 22 of 27 deaths were attributed to sepsis or related multiple organ failure. Most infections were respiratory or abdominal and were microbiologically documented in 50 (68\%) patients. Blood cultures were positive in 29 (39\%) patients. Fortythree (58\%) cases of sepsis were secondary to gram-negative bacilli, with 28 infections due to difficult-to-treat pathogens (P. aeruginosa $(\mathrm{n}=15)$; Enterobacter spp. $(\mathrm{n}=$ 8); Serratia marcescens $(\mathrm{n}=2)$; Citrobacter freundii, Hafnia alvei, or Morganella morganii $($ each $\mathrm{n}=1)$ ).

\section{Pharmacokinetic data}

The median amikacin dose was 1,750 mg (range, 1,125 to $3,000 \mathrm{mg}$ ). Main PK parameters for amikacin were $\mathrm{V}_{\mathrm{ss}}$ 0.41 [0.29 to 0.51$] \mathrm{L} / \mathrm{kg}, \mathrm{t}_{1 / 2} 4.6$ [3.2 to 7.8 ] hours, and CL 1.98 [1.28-3.54] $\mathrm{ml} / \mathrm{min} / \mathrm{kg}$ (Table 2). Median serum concentrations of amikacin were $0,72.7$ (61.7 to 90.2), 61.5 (48.5 to 73.1), 37.3 (27.7 to 46.5 ), 26.7 (16.4 to 33.8 ), and 6.7 (2.1 to 15.4$) \mu \mathrm{g} / \mathrm{ml}$ at 0 hours, 1 hour (peak), 1 hour 30 minutes, 4 hours 30 minutes, 8 hours, and 24 hours, respectively (Figure 1). Peak serum concentrations were $>64 \mu \mathrm{g} / \mathrm{ml}$ in $52(70 \%)$ patients (Figure 2). For a target $\mathrm{MIC}$ of $8 \mu \mathrm{g} / \mathrm{ml}$, the peak/MIC ratio was $9.6 \pm 3.5$. With this regimen, peak/MIC $>8$ would have been reached in all patients for an MIC of $\leq 4 \mu \mathrm{g} / \mathrm{ml}$. 
Table 1: Patient characteristics, hemodynamic and biologic data on admission, and fluid balance during the first 24 hours

\begin{tabular}{|c|c|}
\hline Variables & Values \\
\hline Age (years) & $63 \pm 13$ \\
\hline Sex (Male/Female) & $50 / 24$ \\
\hline Body Mass Index & $24.7 \pm 4.6$ \\
\hline APACHE II score & $21(16-26)$ \\
\hline SOFA score on admission & $8(5-11)$ \\
\hline Medical/Surgical & $50 / 24$ \\
\hline COPD & $14(19 \%)$ \\
\hline Diabetes & $17(23 \%)$ \\
\hline Heart disease & $39(53 \%)$ \\
\hline Chronic renal insufficiency & $7(9 \%)$ \\
\hline Liver cirrhosis & $11(15 \%)$ \\
\hline Immunosuppressive drugs & $25(34 \%)$ \\
\hline Malignancy & $24(32 \%)$ \\
\hline Community/hospital-acquired infections & $22 / 52$ \\
\hline Severe sepsis/septic shock & $17 / 56$ \\
\hline Mechanical ventilation & $56(76 \%)$ \\
\hline Acute renal failure & $20(27 \%)$ \\
\hline Vasopressor agents & $56(76 \%)$ \\
\hline ICU stay (days) & $14(5-25)$ \\
\hline Overall ICU mortality & $27(37 \%)$ \\
\hline Mean arterial pressure $(\mathrm{mmHg})$ & $70 \pm 14$ \\
\hline Central venous pressure $(\mathrm{mmHg})$ & $10 \pm 5$ \\
\hline $\mathrm{pH}$ & $7.41 \pm 0.12$ \\
\hline $\mathrm{PaO}_{2} / \mathrm{FiO}_{2}$ ratio & $166[112-227]$ \\
\hline $\mathrm{PaCO}_{2}(\mathrm{mmHg})$ & $39 \pm 12$ \\
\hline Lactate (mEq/L) & $2.7[1.7-3.9]$ \\
\hline White blood cells $\left(/ \mathrm{mm}^{3}\right)$ & $11400[8600-20400]$ \\
\hline Hematocrit (\%) & $30.4 \pm 7.6$ \\
\hline Platelets $\left(10^{3} / \mathrm{mm}^{3}\right)$ & 175 [86-292] \\
\hline Bilirubin (mg/dl) & $0.9[0.5-2.0]$ \\
\hline Creatinine (mg/dl) & $1.7[1.1-3.1]$ \\
\hline C-reactive protein (mg/dl) & $17[10-26]$ \\
\hline Creatinine clearance (ml/min) & $54[33-86]$ \\
\hline Fluid balance (ml/24 h) & $2650 \pm 2121$ \\
\hline Fluids IN (ml/24 h) & $4594 \pm 1892$ \\
\hline Fluids OUT (ml/24 h) & $1944 \pm 1621$ \\
\hline
\end{tabular}

Data are expressed as counts (percentage), median (IQR), or mean \pm SD. APACHE, Acute Physiology and Chronic Health Evaluation; COPD, chronic obstructive pulmonary disease; ICU, intensive care unit; SOFA, Sequential Organ Failure Assessment.
Thirty-nine (52\%) patients had a $C_{\min }>5 \mu \mathrm{g} / \mathrm{ml} . \mathrm{C}_{\min }$ $\left(\mathrm{R}^{2}=0.51, P<0.01\right)$ and $\mathrm{CL}\left(\mathrm{R}^{2}=0.41 ; P<0.01\right)$, but not peak concentration, were correlated with $\mathrm{CrCl}$ at inclusion. Moreover, patients with renal dysfunction had higher amikacin levels at 4 hours 30 minutes $(43.9 \pm 11.5$ $\mu \mathrm{g} / \mathrm{ml}$ vs. $31.8 \pm 14.4 \mu \mathrm{g} / \mathrm{ml} ; P<0.001)$ and $24 \mathrm{~h}(15.4(8.0$ to 21.4$) \mu \mathrm{g} / \mathrm{ml}$ vs. 2.6 (1.3 to 6.0$) \mu \mathrm{g} / \mathrm{ml} ; P<0.001)$, as well as lower $\mathrm{CL}$ and increased $\mathrm{t}_{1 / 2}$ and $\mathrm{AUC}$, than had patients with normal renal function. However, the $\mathrm{V}_{\mathrm{ss}}$ and peak concentrations were similar (Table 2).

\section{Impact of weight on peak amikacin concentrations}

Adequate peak concentrations were achieved in six (54\%) of 11 patients with a BMI <20, $23(64 \%)$ of 36 with a BMI of 20 to 25,15 (83\%) of 18 with a BMI from 25 to 30, and eight $(89 \%)$ of nine with a BMI $>30$. Simulation with doses calculated by using the IBW showed that only 35 (47\%) patients would have reached a peak $>64 \mu \mathrm{g} / \mathrm{ml}(P<$ 0.01 compared with a regimen established by using TBW). The use of DW compared with TBW for dose calculation had no effect in terms of adequate peak concentrations (Table 3). When the amikacin dose was calculated by using DW, a dose of $28 \mathrm{mg} / \mathrm{kg}$ would have been necessary for $70 \%$ of patients to have achieved the desired peak concentration.

\section{Simulations with other regimens}

By using a simulated amikacin dose of $15 \mathrm{mg} / \mathrm{kg}$, we observed that only seven (9\%) patients would have reached a peak concentration $>64 \mu \mathrm{g} / \mathrm{ml}(P<0.001$ vs. 25 $\mathrm{mg} / \mathrm{kg}$ TBW dose), whereas for a $30-\mathrm{mg} / \mathrm{kg}$ regimen, $80 \%$ of patients would have achieved the optimal peak concentration (Table 3). Interestingly, the proportion of patients with a $\mathrm{C}_{\min }>5 \mu \mathrm{g} / \mathrm{ml}$ would have been similar to the 15 and $25 \mathrm{mg} / \mathrm{kg}$ regimens ( $39 \%$ vs. $52 \% ; P=0.1$ ).

\section{Correlation with clinical variables}

The peak of amikacin was not correlated with or predicted by any biologic, hemodynamic, or clinical variable, including age, mechanical ventilation, APACHE II or SOFA score at admission, presence of shock, maximal dose of vasopressor agents, fluid balance, or renal failure. Patients with a peak concentration $>64 \mu \mathrm{g} / \mathrm{ml}$ had similar characteristics to patients with peak concentrations $<64$ $\mu \mathrm{g} / \mathrm{ml}$ (Table 4).

\section{Discussion}

This is the first study in which a higher dose of amikacin was prospectively validated in sepsis patients after a PK analysis. We showed that, because of PK alterations, a loading dose of $\geq 25 \mathrm{mg} / \mathrm{kg}$ of amikacin is necessary to achieve therapeutic peak concentrations in patients with severe sepsis or septic shock. Antimicrobials PKs in ICU patients are significantly different from those in healthy 
volunteers or less severely ill patients [14,31,32]. Increased cardiac index and interstitial fluid shifts in sepsis result in a larger volume of distribution $\left(\mathrm{V}_{\mathrm{d}}\right)$, which may reduce plasma antibiotic levels [33]. Decreased protein binding can result in higher free-drug concentrations, and organ dysfunction may decrease drug metabolism and clearance [33]. Finally, infections, especially when acquired in the ICU, are often caused by more-resistant pathogens [34]. For aminoglycosides, peak concentration is determined by the administered dose and by the $\mathrm{V}_{\mathrm{d}}$ [30]. The $\mathrm{V}_{\mathrm{d}}$ of amikacin is between 0.2 and $0.3 \mathrm{~L} / \mathrm{kg}$ in healthy volunteers and in patients with mild infections $[12,20,35]$. In our study, the median $V_{d}$ was $0.41 \mathrm{~L} / \mathrm{kg}$, corresponding to a $>60 \%$ increase when compared with normal ranges. These results confirm data from previous studies. In 200 adult and pediatric ICU patients with severe gram-negative infections, the $\mathrm{V}_{\mathrm{d}}$ of amikacin varied from 0.17 to $0.98 \mathrm{~L} / \mathrm{kg}$, with a mean of $0.37 \mathrm{~L} / \mathrm{Kg}$ [16]. A mean $\mathrm{V}_{\mathrm{d}}$ of $0.47 \mathrm{~L} / \mathrm{kg}$ was reported in 30 ICU patients [17]. In patients with postoperative septic shock, the $V_{d}$ was $0.41 \pm 0.08 \mathrm{~L} / \mathrm{kg}$, a significantly higher value than that in controls $(0.25 \pm 0.01 \mathrm{~L} / \mathrm{kg})$ [36]. The variability of $\mathrm{V}_{\mathrm{d}}$ in sepsis patients is probably multifactorial and depends on the degree of inflammation, vascular permeability, and fluid extravasation $[12,32,37]$. Doses of 15 and $20 \mathrm{mg} / \mathrm{kg}$ produced means of $33.5 \pm 14.8$ and 33.8 $\pm 4.7 \mu \mathrm{g} / \mathrm{ml}$, respectively, in adult ICU patients $[15,16]$. However, the peak obtained with these regimens was largely below the desired concentration of $64 \mu \mathrm{g} / \mathrm{ml}$, suggesting that higher doses of amikacin should be administered to achieve optimal peak levels. Moreover, previous studies on amikacin dose in ICU patients had limited patient samples [17,36,38], were retrospective [10,39], or had exclusion criteria, such as septic shock [15], APACHE II score $>35$ [40], liver cirrhosis [17], or acute renal failure [15-17,40], making it difficult to extrapolate the results to a general septic ICU population.

Our study is the first to provide data on sepsis patients with several comorbidities, high disease severity, and multiple organ dysfunctions, with an ICU mortality rate

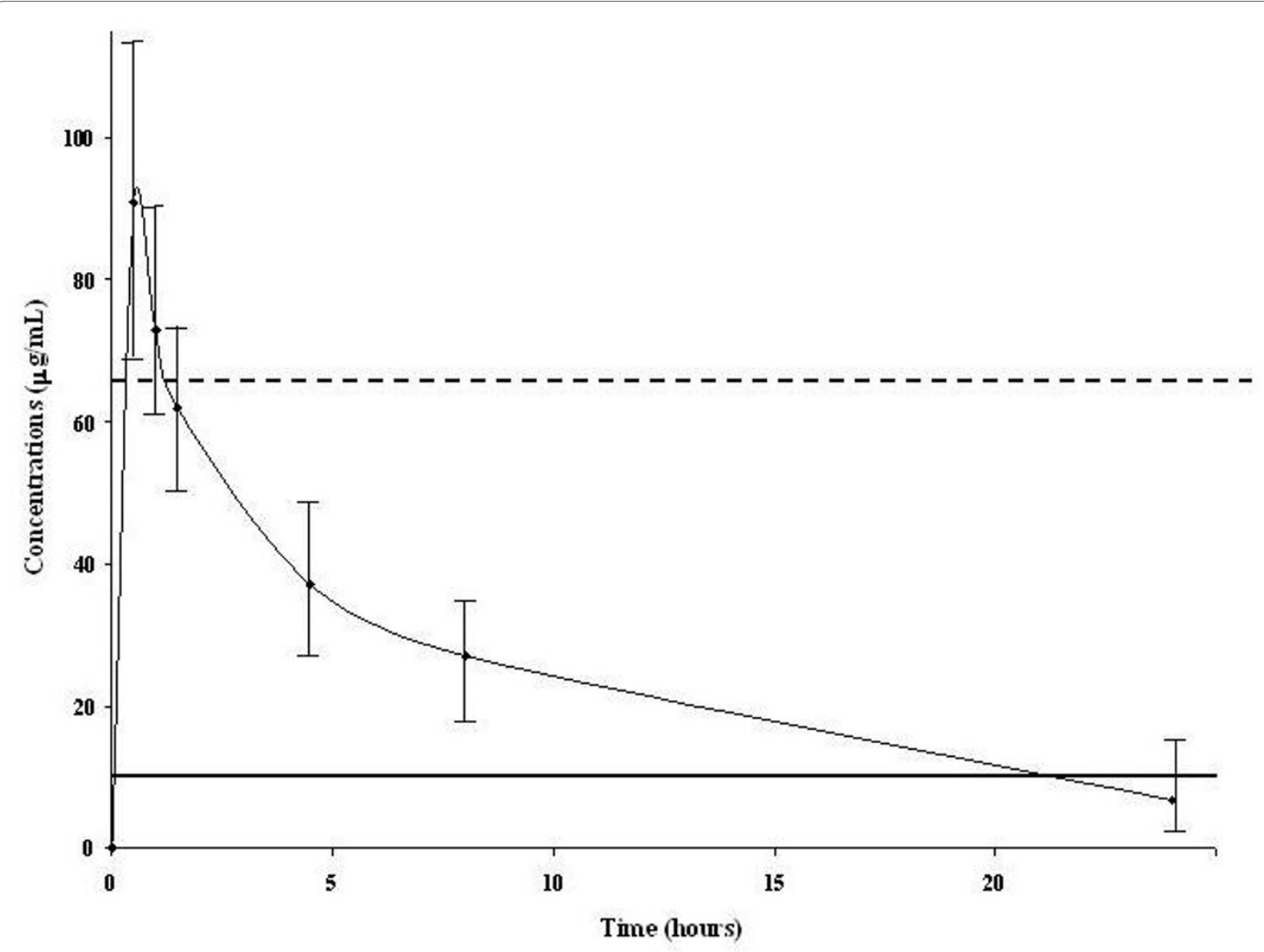

Figure 1 Pharmacokinetic profile of amikacin. Dashed line, peak of $64 \mu \mathrm{g} / \mathrm{ml}$ corresponding to 8 times the clinical breakpoint of the minimal inhibitory concentration (MIC $=8 \mu \mathrm{g} / \mathrm{ml}$, solid line) for gram-negative bacteria. 


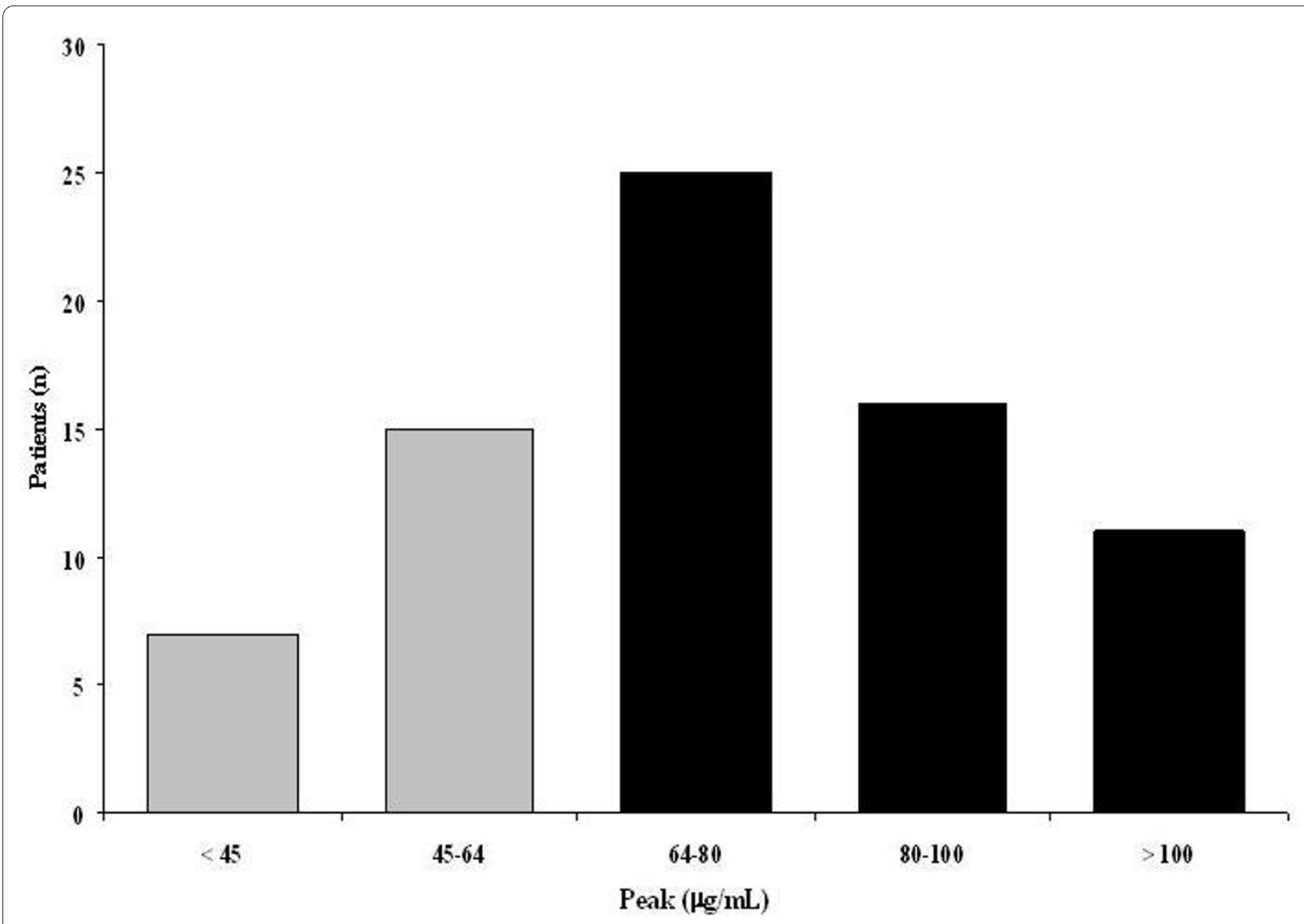

Figure 2 Distribution of peak concentrations. Black bars, peak $>64 \mu \mathrm{g} / \mathrm{ml}$; gray bars, peak $<64 \mu \mathrm{g} / \mathrm{ml}$.

of nearly $40 \%$. This cohort of 74 patients was relatively large and representative of a typical ICU population. Most of the infections were secondary to gram-negative infections, with $20 \%$ being caused by difficult-to-treat bacteria known to be associated with high mortality rates
[41]. This represents the population in which aminoglycoside treatment could be recommended [6].

Assuming a three- to fourfold factor for converting doses of amikacin to gentamicin and tobramycin, it has been suggested that higher doses should be used for these two aminoglycosides in patients with septic shock

Table 2: Amikacin pharmacokinetics in patients with or without renal dysfunction

\begin{tabular}{|c|c|c|c|}
\hline & $\begin{array}{l}\text { All } \\
(n=74)\end{array}$ & $\begin{array}{l}\mathrm{CrCl}<50 \mathrm{ml} / \mathrm{min} \\
(\mathrm{n}=38)\end{array}$ & $\begin{array}{l}\mathrm{CrCl}>50 \mathrm{ml} / \mathrm{min} \\
(\mathrm{n}=36)\end{array}$ \\
\hline $\mathrm{V}_{\mathrm{d} 1}$ (central) (L) & $0.23(0.18-0.28)$ & $0.23(0.19-0.35)$ & $0.22(0.17-0.26)$ \\
\hline $\mathrm{V}_{\mathrm{d} 2}$ (peripheral) $(\mathrm{L})$ & $0.18(0.11-0.23)$ & $0.19(0.12-0.29)$ & $0.18(0.11-0.23)$ \\
\hline $\mathrm{V}_{\mathrm{ss}}(\mathrm{L} / \mathrm{kg})$ & $0.41(0.29-0.51)$ & $0.42(0.31-0.54)$ & $0.40(0.28-0.49)$ \\
\hline $\mathrm{t}_{1 / 2}$ (hours) & $4.6(3.2-7.8)$ & $7.6(4.6-13.2)$ & $3.3(2.5-4.6)^{a}$ \\
\hline $\mathrm{CL}(\mathrm{ml} / \mathrm{min} / \mathrm{kg})$ & $1.98(1.28-3.54)$ & $1.29(0.84-2.01)$ & $3.49(1.94-5.04)^{a}$ \\
\hline $\mathrm{AUC}(\mathrm{mg} \times \mathrm{h} / \mathrm{ml})$ & 798 (478-1285) & $1,177(833-1961)$ & $466(368-763)^{a}$ \\
\hline$C_{\max }(\mu \mathrm{g} / \mathrm{ml})$ & $91.7(73.1-112.8)$ & $91.0(70.6-112.8)$ & $92.3(74.1-109.4)$ \\
\hline Peak ( $\mu \mathrm{g} / \mathrm{ml})$ & 72.7 (61.7-90.2) & $71.5(57.3-86.3)$ & 75.7 (63.1-92.9) \\
\hline$C_{\min }(\mu \mathrm{g} / \mathrm{ml})$ & $6.7(2.1-15.4)$ & $15.4(8.0-21.4)$ & $2.6(1.3-6.0)^{a}$ \\
\hline
\end{tabular}

Data are expressed as median (IQR). ${ }^{a} p<0.001$. AUC, area under the curve; $\mathrm{t}_{1 / 2}$, elimination half-time; $\mathrm{CL}$, clearance; $\mathrm{CrCl}$, creatinine clearance; $\mathrm{V}_{\mathrm{d}}$, volume of distribution; $\mathrm{V}_{\mathrm{ss}}$, total volume of distribution. 
Table 3: Differences in numbers of patients achieving optimal peak or high $\mathrm{C}_{\min }$ concentrations

\begin{tabular}{lll}
\hline Regimen & $\begin{array}{l}\text { Peak }>\mathbf{6 4} \boldsymbol{\mu g} / \mathbf{m l} \\
\mathbf{n}(\%)\end{array}$ & $\begin{array}{l}\mathbf{C}_{\min }>\mathbf{5} \boldsymbol{\mu g} / \mathbf{m l} \\
\mathbf{n}(\%)\end{array}$ \\
\hline $15 \mathrm{mg} / \mathrm{kg} \mathrm{TBW}$ & $7(9)$ & $29(39)$ \\
$25 \mathrm{mg} / \mathrm{kg} \mathrm{TBW}$ & $50(72)$ & $39(52)$ \\
$30 \mathrm{mg} / \mathrm{kg} \mathrm{TBW}$ & $59(79)$ & $43(58)$ \\
$25 \mathrm{mg} / \mathrm{kg} \mathrm{IBW}$ & $35(47)$ & $39(52)$ \\
$25 \mathrm{mg} / \mathrm{kg} \mathrm{DW}$ & $42(56)$ & $39(52)$ \\
\hline
\end{tabular}

Doses were calculated by using total body weight (TBW), ideal body weight (IBW), or IBW with correction factors (DW) for extreme body mass indexes.

$[18,42]$. However, a dose $>7 \mathrm{mg} / \mathrm{kg}$ has not been prospectively validated for these drugs. Our data demonstrate that, with $25 \mathrm{mg} / \mathrm{kg}$ of amikacin, the target peak concentration $(>64 \mu \mathrm{g} / \mathrm{ml})$ was achieved in $70 \%$ of patients. An even higher dose may be necessary in some patients for whom the peak concentration remains below the desired level. Simulation with a standard regimen $(15 \mathrm{mg} / \mathrm{kg})$ of amikacin resulted in insufficient peak concentrations in $>90 \%$ of patients, confirming the need to increase amikacin doses to ensure that adequate peak levels are achieved in sepsis patients.

A relation between the intensity of the septic process and the expansion of the $\mathrm{V}_{\mathrm{d}}$ can be assumed. Marik et al. $[16,43]$ and Lugo-Goytia et al. [39] demonstrated an association between sepsis severity, estimated by the APACHE II score, and aminoglycoside $\mathrm{V}_{\mathrm{d}}$. $\mathrm{V}_{\mathrm{d}}$ was also reported to be correlated with oxygen extraction ratio, serum albumin levels, and adrenergic support in another study [17]. We did not find any relation between $V_{d}$ and any demographic, clinical, hemodynamic, or biologic variable. Our population was analyzed in the early phase of the septic process, and this may explain the difference from previous studies, which were conducted in the steady state. The considerable interindividual variability observed in critically ill patients may also limit the a priori prediction of PK abnormalities and the optimal dose that should be administered to sepsis patients. Optimizing aminoglycoside therapy should, therefore, be achieved by tight serum-concentration monitoring (peak and trough) and rapid dose adjustment [44] according to pathogen MIC. This strategy requires pathogen MIC

Table 4: Differences between patients with optimal $(>64 \mu \mathrm{g} / \mathrm{ml})$ and inadequate $(<64 \mu \mathrm{g} / \mathrm{ml})$ peak amikacin concentrations

\begin{tabular}{lll}
\hline & $\begin{array}{l}\text { Peak }>\mathbf{6 4} \\
(\mathbf{n}=\mathbf{5 2})\end{array}$ & $\begin{array}{l}\text { Peak }<\mathbf{6 4} \\
\text { (n= 22) }\end{array}$ \\
\hline Male & $32(62)$ & $18(81)$ \\
Nosocomial infections & $37(71)$ & $15(68)$ \\
Medical admission & $37(71)$ & $13(59)$ \\
Positive blood cultures & $18(35)$ & $11(50)$ \\
Shock/vasopressors & $40(76)$ & $16(72)$ \\
Mechanical ventilation & $37(71)$ & $19(86)$ \\
Age (years) & $62 \pm 14$ & $64 \pm 13$ \\
APACHE Il score & $20(16-25)$ & $23(16-28)$ \\
SOFA score & $8(5-10)$ & $9(5-11)$ \\
Highest lactate $(\mathrm{mmol} / \mathrm{L})$ & $3.1(1.5-4.8)$ & $2.8(1.3-5.2)$ \\
Creatinine $(\mathrm{mg} / \mathrm{ml})$ & $1.6 \pm 1.1$ & $1.7 \pm 1.3$ \\
Albumin (g/dl) & $2.4 \pm 0.8$ & $2.4 \pm 0.8$ \\
Fluid balance $(\mathrm{ml} / 24 \mathrm{~h})$ & $2,589 \pm 2,153$ & $2,793 \pm 2,085$ \\
\hline
\end{tabular}

Data are expressed as median (IQR), mean ( \pm SD), or counts (percentage). APACHE, Acute Physiology and Chronic Health Evaluation; SOFA, Sequential Organ Failure Assessment. 
measurement and a $C_{\min }<5 \mu \mathrm{g} / \mathrm{ml}$ to optimize the subsequent doses and to avoid drug accumulation.

Physiologic alterations associated with increased BMI affect the aminoglycoside PK. This is due to the variable penetration of these drugs into adipose tissue. Previous studies have validated dosing weight correction factors to normalize predictions of $\mathrm{V}_{\mathrm{ss}}$ in morbidly obese subjects [23] as well as in overweight/underweight patients [24] in a non-ICU population. Also, IBW seems to fit the pharmacokinetics of these antimicrobials better than the total body weight (TBW) to calculate the aminoglycoside regimen $[45,46]$; however, some uncertainty exists in this area [47]. Our results suggest that using a DW-based regimen could result in a relative underdosing of aminoglycoside in critically ill sepsis patients when compared with a TBW-based regimen. Thus, if using IBW, a loading dose even higher than $25 \mathrm{mg} / \mathrm{kg}$ should be considered in this patient population to obtain adequate amikacin peak concentrations. Importantly, a higher dosage should be considered also in patients with a BMI $<20$ to avoid underdosage. We excluded morbidly obese patients (BMI $>40$ ), so that we cannot comment on this particular population.

Our study has some limitations. First, we evaluated the PK profile of amikacin only during the first 24 hours of administration, and thus cannot make any statement with regard to subsequent doses. The $\mathrm{V}_{\mathrm{d}}$ may decrease during therapy when capillary leakage subsides and sepsis resolves [48]. In these circumstances, amikacin doses $<25$ $\mathrm{mg} / \mathrm{kg}$ may be sufficient to achieve therapeutic concentrations.

Second, a control group of patients without sepsis was not included. However, it would have been unethical to expose nonseptic patients, even with increased $V_{d}$, such as in trauma or cardiac surgery [5,49], to a higher dose of a potentially toxic antibiotic drug.

Third, we did not evaluate the evolution of renal function in our population, with amikacin concentrations exceeding the toxicity limit at 24 hours in $>50 \%$ of patients. However, targeting peak amikacin concentrations $>60 \mu \mathrm{g} / \mathrm{ml}$ resulted in the same incidence of nephrotoxicity compared with conventional treatment [40], as long as individualized pharmacokinetic dosing of aminoglycoside was performed to allow a necessary drug-free period. The $\mathrm{CrCl}$ was estimated by using the Crockroft and Gault formula; however, this may overestimate $\mathrm{CrCl}$ because immobility and reduced muscle mass in ICU patients and a more accurate assessment of renal function should have been based on the urinary creatinine excretion [50]. Fourth, we lack information about the clinical and microbiologic response, and follow-up was not continued after ICU discharge, as this was not the primary aim of the study. Clearly, a systematic clinical PK study is required to evaluate the beneficial effects of this strategy on the outcome of sepsis patients.

Finally, we did not directly measure the body weight, and inaccurate weight estimation may have occurred for some of the studied patients [51].

\section{Conclusions}

Patients with severe sepsis and septic shock have an increased $V_{d}$ necessitating an initial dose of $\geq 25 \mathrm{mg} / \mathrm{kg}$ TBW of amikacin to reach therapeutic peak concentrations. Even this regimen resulted in serum concentrations that were too low in one third of our patients. If using DW when calculating amikacin dose, an even higher dose should probably be considered to achieve adequate peak concentrations. The large interindividual PK variability and high amikacin concentrations at 24 hours in patients with renal impairment support the need for monitoring of serum amikacin concentrations in sepsis patients, to optimize peak concentrations, and to prevent, by increasing the dose interval, the potential toxicity of persistently high serum concentrations. It would seem important to evaluate whether this strategy could be beneficial in terms of clinical efficacy and toxicity in the sepsis population.

\section{Key messages}

- A loading dose of $\geq 25 \mathrm{mg} / \mathrm{kg}$ TBW of amikacin is necessary to optimize peak concentrations and increase the bactericidal activity of the drug in patients with severe sepsis and septic shock

- An even higher dosage may be necessary if amikacin regimen is calculated by using DW or in underweight patients $(\mathrm{BMI}<20)$ to avoid underdosage

- Therapeutic drug monitoring is mandatory, as no clinical or biologic variable can predict amikacin pharmacokinetics in this population

\section{Abbreviations}

APACHE: Acute Physiology and Chronic Health Evaluation; AUC: area under the curve; BMI: body mass index; CL: clearance; $\mathrm{CrCl}$ : creatinine clearance; CRP: Creactive protein; DW: corrected body weight; IBW: ideal body weight; MIC: minimum inhibitory concentration; PK: pharmacokinetic; SOFA: sequential organ failure assessment; TBW: total body weight; $V_{d}$ : volume of distribution; $V_{s s}$ : total volume of distribution.

\section{Competing interests}

The authors declare that they have no competing interests.

\section{Authors' contributions}

FJ conceived the study protocol. FST, FJ, PFL, TD, and HS participated in the design and coordination of the study. FST, JLV, and FJ drafted the present manuscript. All authors read and approved the final manuscript.

\section{Acknowledgements}

We thank all the nurses and doctors who contributed to this study. The study was supported by grants from AstraZeneca, Wyeth Pharmaceuticals, GlaxoSmithKline Pharmaceuticals, and Bristol-Myers Squibb. 


\section{Author Details}

'Department of Intensive Care, Erasme Hospital, Université Libre de Bruxelles, Route de Lennik 808, 1070 Bruxelles, Belgium, 2Department of Intensive Care, Cliniques Universitaires St-Luc Avenue Hippocrate 10, 1200 Bruxelles, Belgium, ${ }^{3}$ Department of Intensive Care, Universitair Ziekenhuis Brussel, Laerbeeklaan 101, 1090 Bruxelles, Belgium, ${ }^{4}$ Department of Intensive Care, St-Pierre Hospital, Avenue Reine Fabiola 9, 1340 Ottignies, Belgium, ${ }^{5}$ Department of Clinical Biochemistry and Pharmacokinetics, Cliniques Universitaires, St-Luc Avenue Hippocrate 10, 1200 Bruxelles, Belgium and ${ }^{6}$ Department of Infectious Diseases, Erasme Hospital, Université Libre de Bruxelles, Route de Lennik 808, 1070 Bruxelles, Belgium

Received: 1 January 2010 Revised: 4 March 2010

Accepted: 6 April 2010 Published: 6 April 2010

\section{References}

1. Vincent JL, Taccone F, Schmit X: Classification, incidence, and outcomes of sepsis and multiple organ failure. Contrib Nephrol 2007, 156:64-74.

2. Kollef MH, Sherman G, Ward S, Fraser VJ: Inadequate antimicrobial treatment of infections: a risk factor for hospital mortality among critically ill patients. Chest 1999, 115:462-474.

3. Zaragoza R, Artero A, Camarena JJ, Sancho S, Gonzalez R, Nogueira JM: The influence of inadequate empirical antimicrobial treatment on patients with bloodstream infections in an intensive care unit. Clin Microbiol Infect 2003, 9:412-418.

4. Falagas ME, Kopterides P: Old antibiotics for infections in critically ill patients. Curr Opin Crit Care 2007, 13:592-597.

5. Bochud PY, Glauser MP, Carlet J, Calandra T: Empirical antibiotic therapy for patients with severe sepsis and septic shock. In The Sepsis Text Edited by: Vincent JL, Carlet J, Opal SM. Norwell: Kluwer Academic; 2002:539-558

6. Safdar N, Handelsman J, Maki DG: Does combination antimicrobial therapy reduce mortality in gram-negative bacteraemia? A metaanalysis. Lancet Infect Dis 2004, 4:519-527.

7. Paul M, Silbiger I, Grozinsky S, Soares-Weiser K, Leibovici L: Beta lactam antibiotic monotherapy versus beta lactam-aminoglycoside antibiotic combination therapy for sepsis. Cochrane Database Syst Rev 2006:CD003344

8. Moore RD, Smith CR, Lietman PS: The association of aminoglycoside plasma levels with mortality in patients with gram-negative bacteremia. J Infect Dis 1984, 149:443-448.

9. Moore RD, Smith CR, Lietman PS: Association of aminoglycoside plasma levels with therapeutic outcome in gram-negative pneumonia. $\mathrm{Am} J$ Med 1984, 77:657-662.

10. Moore RD, Lietman PS, Smith CR: Clinical response to aminoglycoside therapy: importance of the ratio of peak concentration to minimal inhibitory concentration. J Infect Dis 1987, 155:93-99.

11. Deziel-Evans LM, Murphy JE, Job ML: Correlation of pharmacokinetic indices with therapeutic outcome in patients receiving aminoglycosides. Clin Pharm 1986, 5:319-324.

12. Pinder M, Bellomo R, Lipman J: Pharmacological principles of antibiotic prescription in the critically ill. Anaesth Intensive Care 2002, 30:134-144

13. EUCAST: Aminoglycosides: EUCAST clinical MIC breakpoints. [http:// wwwsrgaorg/eucastwt/MICTAB/MICaminoglycosideshtml].

14. Fukuoka N, Aibiki M: Recommended dose of arbekacin, an aminoglycoside against methicillin-resistant Staphylococcus aureus, does not achieve desired serum concentration in critically ill patients with lowered creatinine clearance. J Clin Pharm Ther 2008, 33:521-527.

15. Beaucaire G, Leroy O, Beuscart C, Karp P, Chidiac C, Caillaux M: Clinical and bacteriological efficacy, and practical aspects of amikacin given once daily for severe infections. J Antimicrob Chemother 1991, 27(Suppl C):91-103.

16. Marik PE, Havlik I, Monteagudo FS, Lipman J: The pharmacokinetic of amikacin in critically ill adult and paediatric patients: comparison of once-versus twice-daily dosing regimens. J Antimicrob Chemother 1991, 27(Suppl C):81-89.

17. Lugo G, Castaneda-Hernandez G: Relationship between hemodynamic and vital support measures and pharmacokinetic variability of amikacin in critically ill patients with sepsis. Crit Care Med 1997, 25:806-811
18. Rea RS, Capitano B, Bies R, Bigos KL, Smith R, Lee H: Suboptimal aminoglycoside dosing in critically ill patients. Ther Drug Monit 2008, 30:674-681

19. Levy MM, Fink MP, Marshall JC, Abraham E, Angus D, Cook D, Cohen J, Opal SM, Vincent JL, Ramsay G: 2001 SCCM/ESICM/ACCP/ATS/SIS International Sepsis Definitions Conference. Crit Care Med 2003, 31:1250-1256

20. Gilbert DN: Aminoglycosides. In Principle and Practice in Infectious Diseases Edited by: Mandell GL, Bennett JE, Dolin R. New York: Churchill Livingstone; 2000:307-336.

21. Kashuba AD, Nafziger AN, Drusano GL, Bertino JS Jr: Optimizing aminoglycoside therapy for nosocomial pneumonia caused by gramnegative bacteria. Antimicrob Agents Chemother 1999, 43:623-629.

22. Devine BJ: Gentamicin therapy. Drug Intel Clin Pharm 1974, 8:650-655

23. Bauer LA, Blouin RA, Griffen WO Jr, Record KE, Bell RM: Amikacin pharmacokinetics in morbidly obese patients. Am J Hosp Pharm 1980, 37:519-522.

24. Traynor AM, Nafziger AN, Bertino JS Jr: Aminoglycoside dosing weight correction factors for patients of various body sizes. Antimicrob Agents Chemother 1995, 39:545-548

25. Pai MP, Bearden DT: Antimicrobial dosing considerations in obese adult patients. Pharmacotherapy 2007, 27:1081-1091.

26. Knaus WA, Draper EA, Wagner DP, Zimmerman JE: APACHE II: A severity of disease classification system. Crit Care Med 1985, 13:818-829.

27. Vincent JL, Moreno R, Takala J, Willatts S, de Mendonça A, Bruining H Reinhart CK, Suter PM, Thijs LG: The SOFA (Sepsis-related Organ Failure Assessment) score to describe organ dysfunction/failure. Intensive Care Med 1996, 22:707-710.

28. Horan TC, Andrus M, Dudeck MA: CDC/NHSN surveillance definition of health care-associated infection and criteria for specific types of infections in the acute care setting. Am J Infect Control 2008, 36:309-332.

29. Cockcroft DW, Gault MH: Prediction of creatinine clearance from serum creatinine. Nephron 1976, 16:31-41.

30. Roberts JA, Lipman J: Pharmacokinetic issues for antibiotics in the critically ill patient. Crit Care Med 2009, 37:840-851.

31. Zaske DE, Sawchuk RJ, Gerding DN, Strate RG: Increased dosage requirements of gentamicin in burn patients. J Trauma 1976, 16:824-828

32. Hassan E, Ober JD: Predicted and measured aminoglycoside pharmacokinetic parameters in critically ill patients. Antimicrob Agents Chemother 1987, 31:1855-1858.

33. Van Dalen R, Vree TB: Pharmacokinetics of antibiotics in critically ill patients. Intensive Care Med 1990, 16(Suppl 3):S235-S238.

34. Van Eldere J: Multicentre surveillance of Pseudomonas aeruginosa susceptibility patterns in nosocomial infections. J Antimicrob Chemother 2003, 51:347-352.

35. Holford N: Clinical Pharmacokinetics: Drug Data Handbook 3rd edition. Auckland: Adis; 1998.

36. Oparaoji EC, Cornwell EE III, Hekmat E, Lum CR, Adir JS, Siram S: Aminoglycoside volume of distribution in postoperative patients with septic shock. Clin Pharm 1993, 12:131-134.

37. Botha FJ, Bijl P van der, Seifart HI, Parkin DP: Fluctuation of the volume of distribution of amikacin and its effect on once-daily dosage and clearance in a seriously ill patient. Intensive Care Med 1996, 22:443-446.

38. Kihara M, Ikeda Y, Takagi N, Fujita H, Shibata K, Masumori S, Shiratori K, Umemura S, Shionoiri H, Ishii M: Pharmacokinetics of single-dose intravenous amikacin in critically ill patients undergoing slow hemodialysis. Intensive Care Med 1995, 21:348-351.

39. Lugo-Goytia G, Castaneda-Hernandez G: Bayesian approach to control of amikacin serum concentrations in critically ill patients with sepsis. Ann Pharmacother 2000, 34:1389-1394.

40. Bartal C, Danon A, Schlaeffer F, Reisenberg K, Alkan M, Smoliakov R, Sidi A, Almog Y: Pharmacokinetic dosing of aminoglycosides: a controlled trial. Am J Med 2003, 114:194-198.

41. Abbo A, Carmeli Y, Navon-Venezia S, Siegman-Igra Y, Schwaber MJ: Impact of multi-drug-resistant Acinetobacter baumannii on clinical outcomes. Eur J Clin Microbiol Infect Dis 2007, 26:793-800

42. Buijk SE, Mouton JW, Gyssens IC, Verbrugh HA, Bruining HA: Experience with a once-daily dosing program of aminoglycosides in critically ill patients. Intensive Care Med 2002, 28:936-942.

43. Marik PE: Aminoglycoside volume of distribution and illness severity in critically ill septic patients. Anaesth Intensive Care 1993, 21:172-173. 
44. Nicolau DP: Optimizing outcomes with antimicrobial therapy through pharmacodynamic profiling. J Infect Chemother 2003, 9:292-296.

45. Morgan DJ, Bray KM: Lean body mass as a predictor of drug dosage: implications for drug therapy. Clin Pharmacokinet 1994, 26:292-307.

46. Cheymol G: Effects of obesity on pharmacokinetics implications for drug therapy. Clin Pharmacokinet 2000, 39:215-231.

47. Bourguignon L, Goutelle S, Gerard C, Guillermet A, Burdin de Saint MJ, Maire $P$, Ducher M: [Amikacin pharmacokinetics in adults: a variability that question the dose calculation based on weight]. Therapie 2009, 64:47-53.

48. Triginer C, Izquierdo I, Fernandez R, Rello J, Torrent J, Benito S, Net A Gentamicin volume of distribution in critically ill septic patients. Intensive Care Med 1990, 16:303-306.

49. Pea F, Viale P, Furlanut M: Antimicrobial therapy in critically ill patients: a review of pathophysiological conditions responsible for altered disposition and pharmacokinetic variability. Clin Pharmacokinet 2005, 44:1009-1034.

50. Martin JH, Fay MF, Udy A, Roberts J, Kirkpatrick C, Ungerer J, Lipman J: Pitfalls of using estimations of glomerular filtration rate in an intensive care population. Intern Med J 2010 in press.

51. Anglemyer B, Hernandez C, Brice JH, Zou B: The accuracy of visual estimation of body weight in the ED. Am J Emerg Med 2004, 22:526-529.

doi: $10.1186 / \mathrm{cc} 8945$

Cite this article as: Taccone et al., Revisiting the loading dose of amikacin for patients with severe sepsis and septic shock Critical Care 2010, 14:R53

Submit your next manuscript to BioMed Central and take full advantage of:

- Convenient online submission

- Thorough peer review

- No space constraints or color figure charges

- Immediate publication on acceptance

- Inclusion in PubMed, CAS, Scopus and Google Scholar

- Research which is freely available for redistribution

Submit your manuscript at www.biomedcentral.com/submit
C Biomed Central 